\title{
Association between Vitamin D status and Foot ulcer in Type 2 Diabetes Mellitus: a cross sectional study on 300 patients.
}

\author{
S. Ganapathy Kumari1, A. Vijayakumar1, V. Gadadharan1, R. Vijayakumar1, S. M Nair1. \\ 1 Medical Trust Hospital and Diabetes Care Centre, Kulanada, Pathanamthitta, India.
}

\section{Background}

Vitamin D stimulates the cell differentiation and reduces cell proliferation in human body. This helps in cell growth and wound healing

Vitamin D deficiency has been shown to alter insulin synthesis and secretion. It may predispose to glucose intolerance, altered insulin secretion and type 2 diabetes mellitus..

\section{Aim}

To assess the vitamin D levels in diabetic foot ulcer patients and to assess whether there is any relationship between Vitamin D deficiency and presence of diabetic foot ulcer

\section{Method}

300 patients with diabetic foot ulcer were selected randomly for the study.

History, general examination, foot examination details and relevant investigations were noted at the time of initial presentation

A vitamin D level $<10 \mu \mathrm{g} / \mathrm{ml}$ was considered as severe deficiency. Values between 10 to $30 \mu \mathrm{g} / \mathrm{ml}$ were considered as insufficiency and values $>30 \mu \mathrm{g} / \mathrm{ml}$ were considered as normal

\section{Results}

Severe vitamin D deficiency was found in 112 patients $(37.8 \%)$ and insufficiency was present in 147 patients (49.7\%). Only $12.5 \%$ had sufficient vitamin D levels.

$85.5 \%$ of males with diabetic foot ulcer had either severe vitamin D deficiency or insufficiency while $92.2 \%$ of females with diabetic foot ulcer had severe vitamin $\mathrm{D}$ deficiency or insufficiency. And this difference is statistically significant $(p<0.003)$.

$81 \%$ of those with vitamin D deficiency had an uncontrolled $\mathrm{HbAl} \mathrm{c}$ at the time of presentation with ulcer.

Of the patients with severe vitamin D deficiency 23.2\% had nephropathy and of those with vitamin D insufficiency $11.6 \%$ had nephropathy while only $10.8 \%$ of those with no deficiency had nephropathy which is statistically significant. $(\mathrm{P}<0.026)$.

$61.3 \%$ with severe vitamin D deficiency are either overweight or obese.

Patients with ulcer on the plantar aspect of the foot were 3.5 times more likely to have severe vitamin D deficiency as compared to patients with big toe ulcers.

Table 1: Prevalence and severity of Vitamin D Deficiency in patients with Diabetic foot ulcer

\begin{tabular}{|l|l|}
\hline \multicolumn{1}{|c|}{ Vitamin D Status } & \multicolumn{1}{c|}{ Frequency $\mathrm{n}(\%)$} \\
\hline No deficiency $(>30 \mu \mathrm{g} / \mathrm{ml})$ & $37(12.5)$ \\
\hline Insufficiency $(10-30 \mu \mathrm{g} / \mathrm{ml})$ & $147(49.7)$ \\
\hline Severe deficiency $(<10 \mu \mathrm{g} / \mathrm{ml})$ & $112(37.8)$ \\
\hline
\end{tabular}

Table 2: Site of ulcer and Vitamin D levels

\begin{tabular}{|l|l|l|l|}
\hline \multicolumn{1}{|c|}{ Site of ulcer } & $\begin{array}{c}\text { Severe Vit D deficiency } \\
(\%)\end{array}$ & \multicolumn{1}{|c|}{ Odds ratio (95\% CI) } & \multicolumn{1}{c|}{ P-value } \\
\hline Big toe & 41.2 & 1 & \\
\hline Other toes & 41.4 & $1.00(0.37-2.76)$ & 0.99 \\
\hline Plantar aspect of foot & 71.4 & $3.57(1.11-11.48)$ & 0.03 \\
\hline Heel & 57.1 & $1.90(0.54-6.71)$ & 0.32 \\
\hline Dorsum of foot & 65.4 & $2.70(0.93-7.78)$ & 0.07 \\
\hline Others & 72.7 & $3.8(1.19-12.16)$ & 0.02 \\
\hline
\end{tabular}

